\title{
Comment on "Self-trapping on a dimer: Time-dependent solutions of a discrete nonlinear Schrödinger equation",
}

Cruzeiro-Hansson, L.; Christiansen, Peter Leth; Elgin, J. N.

\section{Published in:}

Physical Review B

Link to article, DOI:

10.1103/PhysRevB.37.7896

Publication date:

1988

Document Version

Publisher's PDF, also known as Version of record

Link back to DTU Orbit

Citation (APA):

Cruzeiro-Hansson, L., Christiansen, P. L., \& Elgin, J. N. (1988). Comment on "Self-trapping on a dimer: Timedependent solutions of a discrete nonlinear Schrödinger equation". Physical Review B, 37(13), 7896-7897. https://doi.org/10.1103/PhysRevB.37.7896

\section{General rights}

Copyright and moral rights for the publications made accessible in the public portal are retained by the authors and/or other copyright owners and it is a condition of accessing publications that users recognise and abide by the legal requirements associated with these rights.

- Users may download and print one copy of any publication from the public portal for the purpose of private study or research.

- You may not further distribute the material or use it for any profit-making activity or commercial gain

- You may freely distribute the URL identifying the publication in the public portal 


\title{
Comment on "Self-trapping on a dimer: Time-dependent solutions of a discrete nonlinear Schrödinger equation"
}

\author{
L. Cruzeiro-Hansson and P. L. Christiansen \\ Laboratory of Applied Mathematical Physics, The Technical University of Denmark, DK-2800 Lyngby, Denmark
}

\section{J. N. Elgin}

Department of Mathematics, Imperial College, London SW7 2BZ, United Kingdom

(Received 31 August 1987)

\begin{abstract}
The equivalence between the discrete self-trapping equation for two degrees of freedom, the pendulum equation, and the space-independent $\phi^{4}$ equation is demonstrated.
\end{abstract}

The discrete self-trapping (DST) equation was introduced in Refs. 1 and 2 and has been used to account for the dynamics of small molecules, molecular crystals, selftrapping in amorphous semiconductors, and global proteins. In Ref. 3 it was pointed out that the DST equation is integrable for two degrees of freedom and can be reduced to the pendulum equation. However, no details concerning the reduction to the latter equation were given.

Recently, it has been shown in Ref. 4 that the DST with two degrees of freedom can be reduced to the spaceindependent $\phi^{4}$ equation $\ddot{p}=A p-B p^{3}$. In this Comment we derive the pendulum equation and demonstrate the equivalence with the space-independent $\phi^{4}$ equation.

For two degrees of freedom the DST equation

$$
i \dot{\bar{A}}+\underline{H} \bar{A}=0
$$

can be written as

$$
\begin{aligned}
& i \dot{A}_{1}(t)+\gamma\left|A_{1}(t)\right|{ }^{2} A_{1}(t)+\varepsilon A_{2}(t)=0, \\
& i \dot{A}_{2}(t)+\gamma\left|A_{2}(t)\right|{ }^{2} A_{2}(t)+\varepsilon A_{1}(t)=0 .
\end{aligned}
$$

Here, $A_{1}$ and $A_{2}$ are the probability amplitudes for finding an excitation in the two sites of the system in this case. $\gamma$ and $\varepsilon$ represent the strength of the nonlinear interaction in the system and the coupling between the two sites, respectively.

The density matrix $\underline{\rho}$ with elements

$$
\rho_{j k}(t)=A_{j}(t) A_{k}^{*}(t)
$$

can be rewritten as

$$
\underline{\rho}(t)=\frac{1}{2}\left(\underline{I}+\sum_{j=1}^{3} \underline{\sigma}_{j} r_{j}(t)\right),
$$

where $\underline{I}$ is the identity matrix and $\underline{\sigma}_{j}$ denote the Pauli matrices. From Eqs. (1) and (3) we get

$$
\begin{aligned}
& r_{1}(t)=\rho_{12}(t)+\rho_{21}(t), \\
& r_{2}(t)=i\left[\rho_{12}(t)-\rho_{21}(t)\right], \\
& r_{3}(t)=\rho_{11}(t)-\rho_{22}(t) .
\end{aligned}
$$

Rewriting the matrix $\underline{H}$ as

$$
\underline{H}(t)=\sum_{j=1}^{3} h_{j}(t) \underline{\sigma}_{j}+\frac{\gamma}{2}\left[\left|A_{1}(t)\right|^{2}+\left|A_{2}(t)\right|^{2}\right] \underline{I},
$$

we get

$$
\begin{aligned}
& h_{1}(t)=\varepsilon, \\
& h_{2}(t)=0, \\
& h_{3}(t)=\frac{\gamma}{2}\left(\left|A_{1}\right|^{2}-\left|A_{2}\right|^{2}\right)=\frac{\gamma}{2} r_{3}(t) .
\end{aligned}
$$

In Ref. 3 the DST equation (1) was rewritten as

$$
\underline{\dot{\rho}}(t)=i[\underline{\underline{\rho}}, \underline{H}] \text {. }
$$

Substituting (4), (6), and (7) into (8) the following equations are obtained:

$$
\begin{aligned}
& \dot{r}_{1}(t)=-\gamma r_{2}(t) r_{3}(t), \\
& \dot{r}_{2}(t)=\gamma r_{1}(t) r_{3}(t)-2 \varepsilon r_{3}(t), \\
& \dot{r}_{3}(t)=2 \varepsilon r_{2}(t),
\end{aligned}
$$

implying that $|\bar{r}| \equiv\left(r_{1}^{2}+r_{2}^{2}+r_{3}^{2}\right)^{1 / 2}$ remains constant throughout the interaction (as a consequence of unitarity). Note also that Eqs. (9a) and (9b) imply

$$
r_{1}(t)=-\frac{\gamma}{4 \varepsilon} r_{3}^{2}(t)+\text { const . }
$$

Equations (9) are best solved by writing them first in the form

$\dot{r}_{1}(t)+i \dot{r}_{2}(t)=i \gamma\left[r_{1}(t)+i r_{2}(t)\right] r_{3}(t)-i 2 \varepsilon r_{3}(t)$.

Integration of $(10)$ gives

$$
r_{1}(t)+i r_{2}(t)=\frac{2 \varepsilon}{\gamma}+\alpha \exp \left(i \gamma \int_{t_{0}}^{t} r_{3}\left(t^{\prime}\right) d t^{\prime}\right),
$$

where $\alpha$ and $t_{0}$ are real integration constants.

Since, by $(5 a)$ and $(5 b) r_{1}(t)$ and $r_{2}(t)$ are real, we get

$$
r_{1}(t)=\frac{2 \varepsilon}{\gamma}+\alpha \cos \gamma \int_{t_{0}}^{t} r_{3}\left(t^{\prime}\right) d t^{\prime},
$$

and

$$
r_{2}(t)=\alpha \sin \gamma \int_{t_{0}}^{t} r_{3}\left(t^{\prime}\right) d t^{\prime}
$$

Using (12a) and (5a) at $t=t_{0}$ we obtain

$$
\alpha=\rho_{12}\left(t_{0}\right)+\rho_{21}\left(t_{0}\right)-\frac{2 \varepsilon}{\gamma} \text {. }
$$

Substituting (12b) into (9c) and defining the real vari- 
able $q$ by

$$
q=\gamma \int_{t_{0}}^{t} r_{3}\left(t^{\prime}\right) d t^{\prime}
$$

we get

$$
\ddot{q}=2 \varepsilon \gamma \alpha \sin q,
$$

i.e., the pendulum equation.

In Ref. 4 the space-independent $\phi^{4}$ equation

$$
\ddot{p}=A p-B p^{3}
$$

is derived from the two degrees of freedom DST equation. Here, $p$ is defined as $p \equiv \rho_{11}(t)-\rho_{22}(t)$. Thus

$$
p=r=\frac{\dot{q}}{\gamma} \text {. }
$$

Furthermore, the constants $A$ and $B$ are given by

$$
\begin{aligned}
A= & \frac{\gamma^{2}}{2}\left[\rho_{11}\left(t_{0}\right)-\rho_{22}\left(t_{0}\right)\right]^{2}-4 \varepsilon^{2} \\
& +2 \varepsilon \gamma\left[\rho_{12}\left(t_{0}\right)+\rho_{21}\left(t_{0}\right)\right],
\end{aligned}
$$

and

$$
B=\frac{\gamma^{2}}{2},
$$

in our notation. (Note that Ref. 4 uses $-V$ instead of $\varepsilon$, which is a positive parameter in the DST model.)
We shall now demonstrate that Eq. (16) is equivalent to Eqs. (15) and (13). Integrating (15) and using (17) and (18b) we obtain

$$
B p^{2}=-2 \varepsilon \gamma \alpha \cos q+c,
$$

where $C$ is an integration constant. From the definition of $p$ and (14) it follows that $C=A$ is given by (18a).

Substituting $Q-\sin q / 2$ into (19) we get

$$
B p^{2}=2 \varepsilon \alpha \gamma\left(2 Q^{2}-1\right)+A .
$$

Differentiation of this equation and use of

$$
\dot{Q}=(\dot{q} / 2) \cos (q / 2)=(\gamma p / 2) \sqrt{1-Q^{2}}
$$

yields

$$
\dot{p}^{2}=A p^{2}-\frac{B}{2} p^{4}+\text { const } .
$$

Repeated differentiation now gives

$$
\ddot{p}=A p-B p^{3},
$$

which is the space-independent $\phi^{4}$ equation.

A. C. Scott and J. C. Eilbeck are gratefully acknowledged for informative discussions. The financial support of the C. Gulbenkian Foundation and The Danish Research Council for Scientific and Industrial Research is acknowledged.
${ }^{1}$ J. C. Eilbeck, P. S. Lomdahl, and A. C. Scott, Physica D 16, 318 (1985).

${ }^{2}$ A. C. Scott, P. S. Lomdahl, and J. C. Eilbeck, Chem. Phys. Lett. 113, 29 (1985).
${ }^{3}$ J. H. Jensen, P. L. Christiansen, J. N. Elgin, J. D. Gibbon, and O. Skovgaard, Phys. Lett. A 110, 429 (1985).

${ }^{4}$ V. M. Kenkre and D. K. Campbell, Phys. Rev. B 34, 4959 (1986). 